Revista Pax Domini é licenciada sob

uma Licença Creative Commons.

\title{
A LAICIDADE NO ESTADO BRASILEIRO
}

Edivaldo Lopes de Lima ${ }^{1}$

\section{RESUMO}

O Brasil é um país com uma rica pluralidade cultural e religiosa. Durante boa parte da sua História, o país foi governado com o pulso forte da Igreja Católica (sendo na educação a principal influência), primeiro com os reis portugueses durante o período conhecido como Brasil-Colônia, e depois com os "imperadores", no período imperial. Com o advento da República há uma ruptura nessa relação e o Brasil é proclamado como Estado laico. No entanto, ainda permanecem "resquícios" da ligação entre Estado e Igreja, apesar da norma constitucional, atentando á igualdade religiosa e a convivência.

\section{Palavras-chave}

Laicidade. Estado. Legislação. Pluralidade Religiosa.

\footnotetext{
${ }^{1}$ Edivaldo Lopes de Lima é Capelão Universitário na Faculdade Boas Novas de Manaus/AM.
} 


\section{INTRODUÇÃO}

O Brasil é um país multicultural. Ainda que a maioria dos habitantes seja católica, há uma

pluralidade religiosa evidente e, por conseguinte, um sincretismo religioso. Por isso, o Estado brasileiro deve contemplar todas as culturas e religiões. Este é, na verdade, mais um debate que está relacionado a outros sobre a igualdade entre as pessoas, como de etnia, de gênero, e tantos outros.

A laicidade do Estado Brasileiro é fundamental para esse fim. Por isso é importante esclarecer, de imediato, o que vem a ser um Estado Laico. Abbagnano destaca o laicismo como "o princípio da autonomia das atividades humanas, ou seja, a exigência de que tais atividades se desenvolvam segundo regras próprias, que não lhes sejam impostas de fora, com fins ou interesses diferentes dos que as inspiram.” (ABBAGNANO, 2007, p. 599).

Portanto, esse princípio é universal e pode ser legitimamente invocado em nome de qualquer atividade humana legítima, e não apenas como reivindicação de autonomia do Estado perante a Igreja, mas também "[...] tem o fim de subtrair a ciência ou, em geral, a esfera do saber às influências estranhas e deformantes das ideologias políticas, dos preconceitos de classe ou de raça, etc." (ABBAGNANO, 2007, p. 599).

Estado laico significa não estar influenciado por qualquer esfera fora do que concerne às atribuições estatais.

Nesse sentido, a fim de abordar a laicidade no Estado brasileiro, há que se fazer inicialmente uma abordagem histórica da relação do Estado com a Igreja, destacando a Educação - sempre intimamente relacionada à Igreja. Em seguida, faz-se necessário entender a laicidade (oficial) à luz da legislação. Os símbolos oficiais e não oficiais do Brasil auxiliam nesta compreensão. Por fim, a questão que se põe é como seria possível um Estado com tamanha pluralidade religiosa e cultural estar atrelado à uma Igreja específica.

\section{ASPECTOS HISTÓRICOS}

A colonização no Brasil teve como objetivo a exploração das riquezas. Não havia a intenção da colonização com o objetivo de fixar moradia, como no caso dos ingleses que partiram para a América do Norte. A intenção foi a exploração, ou seja, levar as riquezas do Brasil para a Europa.

A “domesticação” indígena, necessária para a exploração, teve na dita "catequização” grande

Revista Pax Domini | Faculdade Boas Novas | vol. 1 | p. 180 - 190 | jul./dez. 2015 
instrumento de apoio. A Igreja estava junto na exploração do país, ou seja, junto do Estado português. Desta forma, indígenas não podiam igualmente manifestar a sua religiosidade, o mesmo ocorrendo com os escravos trazidos da África. (FAUSTO, 2002).

A justiça, na época das Capitanias era, teoricamente, competência dos donatários que eram administradores, juízes e chefes militares. Convém ressaltar que além das formas convencionais de administração de justiça, havia a presença da Igreja Católica e sua "Justiça Eclesiástica" acolhida e resguardada pela Inquisição. Apesar de não ter existido um Tribunal Inquisitorial do Brasil, a Inquisição teve atuação marcante na Colônia com as chamadas Visitação do Santo Oficio. Em casos mais graves, os acusados eram mandados ao Tribunal Inquisitorial de Lisboa. A Igreja apoiava e tinha apoio nas Câmaras municipais embora não houvesse uma relação institucional oficial. (FAUSTO, 2002).

Importante destacar que a forma mais direta de influência entre Igreja e Estado se deu através da educação. O modelo educacional católico se estabelece através dos portugueses com os padres católicos jesuítas que em 1549, 15 dias após da sua chegada na colônia, fundam a primeira escola brasileira em Salvador. Esses membros da Companhia de Jesus propagavam a fé católica e a educação, sendo os responsáveis pela catequização das indígenas. (ELIAS, 2005).

De acordo com Bello (1998), os jesuítas permaneceram como mentores da educação brasileira durante duzentos e dez anos, até 1759, quando foram expulsos de todas as colônias portuguesas por decisão de Sebastião José de Carvalho, o marquês de Pombal, primeiro-ministro de Portugal de 1750 a 1777. Nesse período, os jesuítas tinham 25 residências, 36 missões e 17 colégios e seminários, além de outros seminários menores e escolas de primeiras instaladas em todas as cidades onde havia casas da Companhia de Jesus. A educação brasileira, com isso, vivenciou uma grande ruptura histórica num processo já implantado e consolidado como modelo educacional. (FAUSTO, 2002).

Posteriormente surgem as ondas migratórias (alemães, italianos, japoneses, etc.) que trazem também sua bagagem cultural e religiosa. Mesmo depois com a independência, a Igreja permanecia ao lado do Estado, tendo forte influência na origem do sistema educacional no Brasil. (BELLO, 1998).

O número de escolas protestantes cresce após a proclamação da República e a consequentemente criação de um Estado laico. Assim, a religião oriunda das reformas passa a ser mais aceita e com isso começa a ganhar uma maior difusão e notoriedade. Isso se deve também as influências e ao estímulo que a pedagogia inovadora trouxe, afinal os colégios confessionais era usados como instrumentos de evangelização. (ELIAS, 2005).

Revista Pax Domini | Faculdade Boas Novas | vol. 1 | p. 180 - 190 | jul./dez. 2015 
Ainda que não atreladas ao Estado, mas as religiões vindas com a chegada dos imigrantes trazem novo fôlego à questão educacional. Os protestantes, com sua ética valorizando o ensino, influenciarão diretamente na reestruturação da escola no Brasil. Por serem consideradas a religião da palavra, as doutrinas reformadas, oferecem o acesso a escrita. Ou seja, a educação ainda é papel de grupos confessionais.

Em 1834 o Ato Adicional à Constituição dispõe que as províncias passariam a ser responsáveis pela administração do ensino primário e secundário. Graças a isso, em 1835, surge a primeira escola normal do país em Niterói. Se houve intenção de bons resultados não foi o que aconteceu, já que, pelas dimensões do país, a educação brasileira se perdeu mais uma vez, obtendo resultados pífios. Em 1880 o Ministro Paulino de Souza lamenta o abandono da educação no Brasil, em seu relatório à Câmara. Em 1882 Ruy Barbosa sugere a liberdade do ensino, o ensino laico e a obrigatoriedade de instrução, obedecendo as normas emanadas pela Maçonaria Internacional. (ELIAS, 2005).

Por meio do Poder Moderador o imperador nomeava os membros vitalícios do Conselho de Estado os presidentes de província, as autoridades eclesiásticas da Igreja oficial católica apostólica romana, o Senado Vitalício. O império era sustentado por 3 pilares: os militares, os proprietários de escravos e a igreja católica. Estes pilares ruíram no final do século XIX. (FAUSTO, 2002).

Em virtude de convivermos em um Estado laico, desde a proclamação da República, há a necessidade da compreensão do pluralismo religioso presente na sociedade brasileira, com vistas a interagir com ele, em uma atitude de respeito e de valorização das diversas opções religiosas nela existentes.

A República separou a Igreja do Estado e constituiu um Estado Laico. Foi implantado o Presidencialismo e o Federalismo, que dava maior liberdade aos Estados. Estes poderiam eleger seus Presidentes (os governadores). Os estados passaram a ter autonomia financeira, tributaria e de contratação de funcionários civis. Poderiam inclusive ter força armada própria. (FAUSTO, 2002).

A partir da Proclamação da República, o Direito mudou de conteúdo e passou a tratar de maneira igual os diferentes. Todos passaram a ter direito ao acesso às funções públicas que, por sua vez, passaram a se reger pelos critérios formais de capacidade e competência. O público vai formalmente se separando do privado.

Assim, o Brasil, desde 1891, com a Constituição Republicana, deixou de ser um Estado Confessional, sendo, há mais de um século, Estado Laico, ou seja, os poderes Executivo, Legislativo ou

Revista Pax Domini | Faculdade Boas Novas | vol. 1 | p. 180 - 190 | jul./dez. 2015 
Judiciário, em todos os seus níveis. A Igreja passa a não ter poder sobre o Estado, de qualquer natureza. (FAUSTO, 2002).

Por outro lado, também o Estado não tem autoridade sobre a organização religiosa, ou seja, o Estado brasileiro não pode interferir em normas da igreja pelo mesmo motivo, por ser laico, conforme pondera Garcia:

\begin{abstract}
Adicione-se que o Novo Código Civil estabelece que é direito da Organização Religiosa, na condição de pessoa jurídica de direito privado, auto-regulamentar-se, criando normas internas de funcionamento, sobretudo regramentos que atinem especificamente sobre questões eclesiásticas, religiosas, espirituais, de fé, que devem estar contidas no Estatuto Social da Igreja, sendo que estas não podem contrariar a ordem jurídica vigente, respeitando a dignidade da pessoa humana, às quais estão sujeitos todos os fiéis, membros, congregados e freqüentadores. (GARCIA, s/d, s/p.).
\end{abstract}

Para exemplificar o desvencilhamento do Estado e da Igreja podemos citar a instituição do casamento civil e secularização dos cemitérios, que passaram a ser administrados pelos municípios. Com isso não havia mais a necessidade de se ter uma vida totalmente pautada dentro da conduta religiosa católica, já que a partir desse momento existia a liberdade de escolha entre outros tipos cultos.

Os missionários estrangeiros que vinham de outros países para poder pregar o evangelho, ganhavam espaço para poderem exercer o objetivo maior que era "arrebanhar almas para o Senhor pautados na verdadeira salvação”. Aí estava o modelo protestante. (ELIAS, 2005).

\title{
LIBERDADE RELIGIOSA E ESTADO LAICO
}

A liberdade religiosa está prevista em nossa Carta Magna, a Constituição de 1988.

\begin{abstract}
A Constituição Federal em seu artigo $5^{\circ}$ (que trata das garantias individuais), inciso VI, afirma que é inviolável a liberdade de consciência e de crença, sendo assegurado o livre exercício dos cultos religiosos e garantida, na forma da lei, a proteção aos locais de liturgias. O que significa dizer que cada brasileiro pode ter qualquer crença e seguir as suas regras, podendo até mesmo não ter crença alguma, pois todos são iguais perante a lei e o Direito tem que aceitar tais diferenças. Argumento que é reforçado porque o Brasil é um Estado Democrático de Direito (art. $1^{\circ}$, caput, CF). (ALVES, 2009, p. 5).
\end{abstract}

Mais adiante, em seu artigo 19, a Constituição destaca:

Revista Pax Domini | Faculdade Boas Novas | vol. 1 | p. 180 - 190 | jul./dez. 2015 
Art. 19. É vedado à União, aos Estados, ao Distrito Federal e aos Municípios:

I - estabelecer cultos religiosos ou igrejas, subvencioná-los, embaraçar-lhes o funcionamento ou manter com eles ou seus representantes relações de dependência ou aliança, ressalvada, na forma da lei, a colaboração de interesse público;

Enfim, o Estado é laico, não podendo estabelecer relações com cultos religiosos ou igrejas. Conforme Abbagnano (2007, p. 600), o Estado Laico “[...] não atende ao interesse deste ou daquele grupo político, religioso ou ideológico, mas ao interesse de todos. Contanto que o interesse de todos seja o desenvolvimento harmônico das atividades que asseguram a sobrevivência do homem no mundo."

O Estado é igualitário e é o guardião dos direitos fundamentais e tem o dever de respeitar, proteger e promover a integridade do ser humano. São fundamentos do estado democrático de direito que constituem a República Federativa do Brasil, expressos na Constituição Federal de 1988, em seu artigo $1^{\circ}$, Dos Princípios Fundamentais.

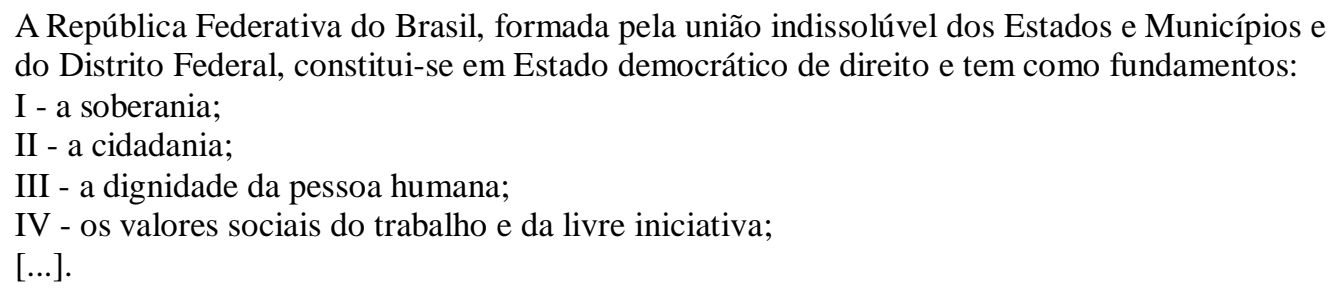

O Brasil tem, portanto, a liberdade de expressão estabelecida e, acima de tudo, a soberania, a cidadania, a dignidade da pessoa humana, entre outros aspectos, como direito dentro de um Estado democrático. Esse Estado, por sua vez, possui seus símbolos, ratificando-se o caráter não religioso. O símbolo, senha, sinal ou marca é uma representação que transporta a mente das pessoas de alguma coisa conhecida para outra, bem diferente dela mesma, mantendo ambas uma identidade estabelecida por tradição ou convenção. (LUZ, 2005).

Os símbolos que representam países e nações pretendem manifestar sua autonomia política. São representações visuais, verbais ou sonoras de um povo, dos seus valores, dos seus objetivos e da sua história. O Brasil possui como símbolos a Bandeira, o Hino, o Selo e o brasão das Armas Nacionais, oficializados na Lei $\mathrm{n}^{\mathrm{o}} 5.700$, de $1^{\circ}$ de setembro de 1971, além de cores nacionais, animais, plantas ou flores heráldicas que estejam relacionados com os itens acima. (LUZ, 2005).

Entre os símbolos não oficiais há os mitos, épicos, pratos e trajes típicos; instrumento musical, danças e músicas folclóricas; herói, monumentos e vários outros emblemas, incluindo plantas, animais e outros

Revista Pax Domini | Faculdade Boas Novas | vol. 1 | p. 180 - 190 | jul./dez. 2015 
objetos associados com a nação. (LUZ, 2005).

A polêmica se cria pela tradição católica brasileira, quando se confunde a inserção de símbolos pelo Estado e pela Igreja Católica. A CNBB reporta toda uma cronologia que demonstra a força da Igreja Católica no Brasil ao fincar suas imagens e símbolos. Em 1904, no dia 08 de setembro, o Papa Pio X, traduzindo o sentimento do povo e atendendo ao pedido de Dom Joaquim Arcoverde, feito em nome do episcopado brasileiro, autorizou, como era usual na Igreja para imagens e quadros insignes, a coroação solene da imagem de Nossa Senhora Aparecida.

No dia 17 de julho de 1930, o Papa Pio XI, atendendo ao pedido dos Bispos brasileiros, assinou o Decreto de Proclamação de Nossa Senhora Aparecida como Padroeira do Brasil. Ou seja, um decreto da Igreja, e não do Estado brasileiro.

Em 1931, no dia 16 de julho, na então Capital do Brasil, na cidade do Rio de Janeiro, o Presidente da República, o senhor Getúlio Vargas, acompanhado de todo o seu Ministério, autoridades diplomáticas, civis, militares e eclesiásticas e de uma grande multidão de fiéis, comemoraram solenemente Nossa Senhora Aparecida, Padroeira do Brasil.

Maria é venerada e amada pelo povo brasileiro, de norte a sul, de leste a oeste e invocada com os mais variados títulos, sendo o título de Nossa Senhora Aparecida - que o povo lhe deu espontaneamente - o mais querido e invocado com mais carinho.

Outros países do mundo - e até mesmo Continentes - tem seu padroeiro. A Igreja proclamou Santa Joana D'Arc, padroeira de França; São Tiago, padroeiro da Espanha. O Papa Pio X declarou Nossa Senhora de Guadalupe "Celestial Padroeira da América Latina”. Paulo VI proclamou São Bento padroeiro da Europa e João Paulo II acrescentou São Cirilo e Metódio, Santa Brígida da Suécia, Santa Catarina de Sena e Santa Edith Stein.

Diante disso, questiona a $\mathrm{CNBB}^{2}$, por que o Brasil, o país mais católico da atualidade não tem direito de ter sua padroeira? "Nossa Senhora Aparecida tem sido, para muitos de nosso povo, inspiração de um estilo de vida solidária, fraterna, de atenção e acolhida ao outro, especialmente, aos mais pobres. Sua presença e devoção têm sido um elo de união e de integração entre todas as etnias, e nunca de divisão."3

Continua a CNBB defendendo que a iniciativa de propor à Câmara Federal retirar o título de Nossa Senhora Aparecida como padroeira do Brasil é descabida, uma vez que não foi a câmara quem o outorgou a

\footnotetext{
${ }^{2}$ http://www.cnbb.org.br/articulistas/dom-raymundo-damasceno-assis/2921-padroeira-do-brasil.

${ }^{3}$ http://www.cnbb.org.br/articulistas/dom-raymundo-damasceno-assis/2921-padroeira-do-brasil.
}

Revista Pax Domini | Faculdade Boas Novas | vol. 1 | p. 180 - 190 | jul./dez. 2015 
Nossa Senhora Aparecida tal título, mas a Igreja, “[...] além de tal proposta ofender o sentimento religioso do povo brasileiro, e em nada contribuir para tornar melhor a vida de nosso povo; antes muito pelo contrario, Nossa Senhora Aparecida é a Rainha e a Padroeira do Brasil por proclamação da Igreja e do povo brasileiro!"4

Porém, o título de padroeira do Brasil é consagrado à Nossa Senhora Aparecida na Lei 6.802, de 30/06/1980, pelo então Presidente João Figueiredo, declara Feriado Nacional o dia 12 de outubro, consagrado à Nossa Senhora Aparecida, Padroeira do Brasil, para culto público e oficial.

E, também, a Lei 9.093, de 12/09/1995, em seu artigo $2^{\text {o: }}$ : são feriados religiosos os dias de guarda, declarados em Lei Municipal, de acordo com a tradição local e em número não superior a quatro, incluída a Sexta-feira da Paixão.

Nesse ponto entra em questão justamente, por um lado, a liberdade de crença, ainda que de minorias, e, consequentemente, a garantia dos direitos fundamentais mencionados, como a soberania de cada indivíduo. O que se verifica, ainda, é que não se trata de minorias religiosas somente, mas de uma pluralidade religiosa, além de ser sincrética. A existência de símbolos religiosos oficiais seria uma afronta a esse sincretismo religioso.

\section{PLURALIDADE RELIGIOSA BRASILEIRA, DEMOCRACIA E LAICISMO}

Apesar do Estado laico a partir da República, conforme Alves,

Não podemos negar ou até mesmo contestar a enorme influência da Igreja na Idade Média e que as duas instituições, Igreja e Estado, sempre andaram muito próximos. Mas desde que foi implantada a República em nosso país, ele se apresenta, ou ao menos tenta, como um Estado Laico e deve zelar pelos direitos dos cidadãos. (ALVES, 2009, p. 2).

Porém, para um estado democrático de direito, com lugar para todos sem privilegiar a um determinado pensamento,

O requisito fundamental para uma sociedade democrática é o caráter laico do Estado, sua total independência perante as instituições eclesiásticas, única forma existente de se garantir o predomínio do interesse comum sobre os interesses particulares e a liberdade absoluta de crenças e práticas religiosas aos cidadãos. (ALVES, 2009, p. 3).

Esse caráter laico é que possibilita a harmonia na pluralidade religiosa brasileira. Sem a representação religiosa, ou sentimento religioso, o Estado não corre o riso de coagir, ainda que inconscientemente, a população a integrar tal pensamento religioso.

\footnotetext{
${ }^{4}$ http://www.cnbb.org.br/articulistas/dom-raymundo-damasceno-assis/2921-padroeira-do-brasil.

Revista Pax Domini | Faculdade Boas Novas | vol. 1 | p. 180 - 190 | jul./dez. 2015 
Pertinente é a conclusão de Abbagnano (2007, p. 600) sobre o laicismo, quando afirma que as administrações políticas que favorecem determinados grupos de cidadãos em prejuízo de outros, seja pelas suas crenças religiosas, são simplesmente ineficientes e corruptas, não podendo reivindicar méritos "religiosos". Da mesma forma, os poderes judiciários que não aplicam com escrúpulo e equidade a lei vigente do Estado, não oferecem garantias a ninguém, porque também são ineficientes e corruptos.

A questão não está no fato de um influenciar ao outro, afinal, somos diariamente influenciados e convencidos em diversos aspectos das nossas vidas. A questão está em respeitar ao outro.

Pensando de uma forma mais global, pode-se destacar Samuel Huntington (1993) e sua obra polêmica “O Choque de Civilizações". Nesta obre ele defende que os seres humanos são divididos de acordo com critérios culturais - ocidentais, islâmicos, hindus e assim por diante. Não existe civilização universal. Em vez disso, o que há são blocos culturais, cada qual delimitado dentro do seu próprio conjunto de valores.

$\mathrm{O}$ argumento central de Huntington encontra-se nos conflitos pós queda do Muro de Berlim, que seriam engendrados por diferenças culturais. Depois de conflitos entre príncipes, Estados-Nação e ideologias, chegara a hora das civilizações. O choque se daria entre as civilizações do islã e o ocidente.

A menção desta obra controversa tem como motivo não o alerta para um choque de culturas no Brasil, ou de crenças. Ainda mais que o que se observa é o choque no plano capital, e menos no cultural e religioso, como defendeu Huntington.

O Brasil, de dimensões continentais, povoado pela minoria indígena (antes a maioria, nativa), por afrodescendentes, imigrantes do velho mundo, além de outras etnias, é pluricultural e, consequentemente, plurirreligioso. Temos "várias civilizações" que formam uma só. Gilberto Freire (2013) já apontava nessa direção em seus estudos na primeira metade do século passado.

Assim, a convivência harmoniosa se faz mister para que não aconteça aqui qualquer tipo de choque. Além do que, o laicismo considerado em sua estrutura conceitual e histórica, não tem qualquer caráter de antagonismo a qualquer forma de religiosidade, nem mesmo ao catolicismo. (ABBAGNANO, 2007).

\section{CONSIDERAÇÕES FINAIS}

A Igreja e o Estado são separados no Brasil. Um não interfere na organização administrativa do outro. Isso do ponto de vista "oficial”. No entanto, a população tem uma forte religiosidade, caracterizada pelo sincretismo religioso. A religião faz parte do cotidiano do brasileiro.

Desta forma, a existência de símbolos religiosos oficiais é, por um lado, uma afronta a esse sincretismo religioso e, por outro, pretexto para conflitos entre a pluralidade religiosa. Conflitos têm surgido no Brasil de

Revista Pax Domini | Faculdade Boas Novas | vol. 1 | p. 180 - 190 | jul./dez. 2015 
forma mais violenta no que se refere à política e ao futebol. Ainda que o povo se mostre pacífico para questões culturais e religiosas, por que deixar motivo para provocar o contrário?

Além do que, a convivência harmoniosa não é somente um preceito cristão, mas de todas as religiões, apesar dos fundamentalismos.

A Constituição brasileira, ao declarar a laicidade do Brasil, a liberdade de crença, e assegurar direitos fundamentais, acaba por ser também afrontada por leis que preveem feriados religiosos e de culto a determinada imagem.

O fato de retirar símbolos religiosos das repartições públicas em nenhum momento seria um ato anticristão, mas o contrário, uma atitude de respeito e fraternidade para com o próximo, atitudes amplamente pregadas pelas religiões. Temos que lutar para que a norma prevaleça sobre o valor.

O debate continua nas esferas política e religiosa. Porém, que este debate não siga por caminhos desarmoniosos, que não se prolongue, e que contemple o direito de todos.

\section{REFERÊNCIAS}

ABBAGNANO, Nicola. Dicionário de Filosofia. São Paulo: Martins Fontes, 2007.

ALVES, Ciro Winston Carneiro. Brasil, um Estado Laico de direito? V Encontro de Iniciação

Científica. Faculdade 7 de Setembro. Fortaleza, 2009. Disponível em:

http://www.fa7.edu.br/recursos/imagens/File/direito/ic/v_encontro/brasilumestado.pdf. Acesso em 25 fev. 2014.

BRASIL. Constituição (1988). Constituição da República Federativa do Brasil de

1988. Disponível em:

http://www.senado.gov.br/legislacao/const/con1988/CON1988_05.10.1988/CON1988.pdf. Acesso em: 10 fev. 2013.

CÉSAR, Elben M. Lenz. História da evangelização do Brasil, dos jesuítas aos neopentecostais. Viçosa: Ultimato, 2000.

ELIAS, Beatriz Vicentini. Inovação americana na educação do Brasil. Nossa História, São Paulo, n. 23, p. 81-83, set. 2005.

FAUSTO, Boris. História Concisa do Brasil. São Paulo: Universidade de São Paulo/Imprensa Oficial do Estado, 2002.

FREIRE, Gilberto. Casa Grande e Senzala. 52 ed. São Paulo: Global, 2013.

Revista Pax Domini | Faculdade Boas Novas | vol. 1 | p. 180 - 190 | jul./dez. 2015 
GARCIA, Gilberto. Estado laico: fundamento da República Federativa do Brasil. Disponível em: http://www.direitonosso.com.br/artigo22.htm. Acesso em 23 fev. 2014.

GARRIDO, Stella. A educação confessional protestante no Brasil. Rio de Janeiro, 2005. Pedagogia em Foco. Rio de Janeiro, ago. 2006. Disponível em: <http://www.pedagogiaemfoco.pro.br/heb13.htm>. Acesso em: 23 fev. 2014.

HUNTINGTON, Samuel. O Choque de Civilizações. São Paulo: Objetiva, 1993.

LUZ, Milton. A História dos Símbolos Nacionais. Brasília: Ed. Senado Federal, 2005.

ZYLBERSZTAJN, Joana. O princípio da laicidade na Constituição Federal de 1988. (Tese de Doutorado). USP, 2012. 